\title{
A New Method of Elements Arrangement to Reattach the F- Block Elements of Lanthanides and Actinides in the IUPAC's Periodic Table of Elements
}

\author{
Al Ossmi LHMi ${ }^{1}$ and Chasib $\mathrm{K} \mathrm{F}^{2 *}$ \\ ${ }^{1}$ College of Engineering, University of Thi-Qar, Iraq \\ ${ }^{2}$ Department of Petroleum \& Gas Engineering, University of Thi-Qar, Iraq
}

*Corresponding author: Khalid Farhod Chasib, Petroleum \& Gas Engineering Department, Collage of Engineering, University of Thi Qar, Iraq, Tel: +964 $790 \quad 2 \quad 89 \quad 80$ 18; Email: khalid_farhod@utq.edu.iq

\author{
Research Article \\ Volume 3 Issue 4 \\ Received Date: October 25, 2019 \\ Published Date: November 20, 2019 \\ DOI: $10.23880 /$ macij- 16000148
}

\section{Abstract}

The periodic table is a tabular arrangement of the chemical elements, ordered by their atomic number, and recurring chemical properties, whose structure shows periodic trends. However, the current periodic table shows a gaps and separated groups of elements in which the f-block elements of Lanthanides and Actinides are split. Keeping the current the atomic number arrangements of groups and periods, this research has proposed new method of elements arrangement, in which the separated f-block elements of Lanthanum, (Lanthanides \& Actinides) were emphasized to their proper position in the table rather than remaining exiled. This new Method of elements arrangement proposed in this research to fit with periodic system of elements in the IUPAC's Periodic Table. The main outcome is to introduce layout regularity, which may reflect the regularity of the periodic law more faithfully. In this research, elements are placed at groups and periods according to atomic numbers which were horizontally displayed into 7 Periods and 12 Groups vertically, this displays in addition to 20 horizontal coordination (named as Nada involved in this study) to determine and dispense altogether the elements positions at the periodic system, determining and dispensing altogether the elements positions at this 3D-modified periodic table. Application of this 3D-modified table helps to determine the atomic number to any element at any part at the main body of the periodic table. In addition, the relationship of f-block elements to the other blocks of the periodic table also becomes easier to see. In addition, this method extensible to expand future table and determining the atomic number and positions of the 55 future elements starting from 119 till the element of 136, at the main body of the IUPAC's Periodic Table.

Keywords: 3D-modified periodic table; f-block Elements; Lanthanides and Actinides; IUPAC 


\section{Medicinal \& Analytical Chemistry International Journal}

\section{Introduction}

The periodic table is the form in which the elements are arranged vertically and horizontally includes periods (shown horizontally) and groups (shown vertically) according to the atomic number so that periodic properties of the elements (chemical periodicity) are made clear. The periodic table is a masterpiece of organized chemical information. However, there is no one single or best structure for the periodic table, but most standard form and the evolution of chemistry's periodic table into the current form of the IUPAC's is very useful and the most common and an astonishing achievement.

Everything is made of atoms, and about of 118 different elements was discovered yet, these elements individually have been named and described by symbols, and according to atomic number they all were tabulated into rows (Periods) and columns (Groups) in the periodic table. In the early years of the $17^{\text {th }}$ century, when new isotopes of many elements were discovered and about only 60 elements were known, Robert Boyle in 1661 proved that elements are formed by atoms. Building on the element's properties, Johann Wolfgang Dobereiner achieved in 1829 a form of arrangement to the known elements into families or Triads, and in 1865 a new step came by John Newlands who noticed that element properties were more similar to the following element, which was named the Octaves, unfortunately there was not a suitable patterns to fit with Newlands, and this step was rejected as it was not fitting with the attitude of British chemical society [1-6].

There was not a really advanced step till the 1869 when Russian chemistry professor Dmitri Mendeleev achieved a revolutionary improvement in the main body of the periodic table of elements. Mendeleev published his tabulated element in a paper in which he drawn a tabular arrangement of the chemical elements as each the 63 known elements were arranged in groups according to their properties, this step allowed him to recognize that there is a clear pattern in which the elements were columned whenever the atomic mass number was decreased [7]. However, Mendeleev left gaps in his table whenever he did not found the suitable elements to fill these gaps, thus he was able to have predictions about the properties to the missed elements, and he also gave detailed predictions for the properties of elements he had earlier noted were missing, but should exist. The first outcomes from Mendeleev's table came in 1875 when Gallium element was discovered to fill the gap according to predicted properties predicted by Mendeleev's table, later Germanium and Scandium elements also proved the Mendeleev's table predictions filling the gaps $[8,9]$.

In 1913, the second revolutionary improvement in the periodic table achieved by Henry Moseley, by rearranging the table according to increasing in the atomic number instead the previous indication of the atomic mass number. Moseley's table was internationally adopted as it allowed successfully adding all current and these new discovered elements with their predicted properties, and his organization of the periodic table can be used to derive relationships between the various element properties, but also the predicted chemical properties and behaviour of undiscovered or newly synthesized elements. More advanced development was added to the periodic table by Glenn Seaborg, an American scientist. In 1945 Seaborg made the suggestion that the actinide elements, like the lanthanides, were filling an f sub-level $[10,11]$. Seaborg's suggestion was found to be correct and he subsequently went on to win the 1951 Nobel Prize in chemistry for his work in synthesizing actinide elements. In 2010, a joint Russia-US collaboration claimed to have synthesized six atoms of element 117 (Tennessine), making it the most recently claimed discovery $[12,13]$. It, along with element 113 (Nihonium), element 115 (Moscovium), and element 118 (Oganesson), are the four most recently named elements, whose names all became official by the International Union of Pure and Applied Chemistry's (IUPAC) on 28 November 2016 [14-16].

The most radical development to take place in contemporary research on the periodic table has been a willingness to challenge tradition by questioning whether the periodic system should be displayed in a twodimensional form and whether it should even be displayed as a table. Nevertheless, there is no one single or best structure for the periodic table. Most standard formats of the periodic table generally place the f-block elements below the main body of the periodic table. Even the current periodic table adopted by IUPAC is not a perfect form; the table has gaps in its main body such as these in columns and rows between Hydrogen and Helium (gaps from Period 1 till 18), in addition to the separation in the table body between the $6^{\text {th }}$ and $7^{\text {th }}$ Groups, and the intersection at $3^{\text {rd }}$ Group. Also, there are two huge gaps in elements list after the elements $56^{\text {th }}$ and $88^{\text {th }}$, in which, 28 elements in the f-block of Lanthanum are split off the table body as all were individually located down the main body of the table. The result is a gap in the element series starting by the element number 56 till 


\section{Medicinal \& Analytical Chemistry International Journal}

number 72, and also from element number 88 till 104, both these tow gaps are containing elements of Lanthanides and Actinides involved in the central body of the table at Periods 6 and 7, and snapped with Group 3. Thus, the IUPAC's modern periodic table unconnectedly placed the f-block elements below the main body of the periodic table leaving two gaps split off the main body of the table. Obviously, this separation in the f-block elements will be increased in future whenever additional future elements needed to be listed in the table.

Building on these points, this research presents a new improvement in the current periodic table to tackle these gaps and split group of Lanthanum without doing any changes in the systematic arrangement of the IUPAC's modern periodic table. In fact the solution built on viewing the periodic table by $3 \mathrm{~d}$-dimentional views and systemizing the f-block element to be listed into the main body of table at the same position to its elements in which the f-block elements are systemized into their natural position between the $s-$ and d-blocks. Form this arrangement, f-block elements of Lanthanides and Actinides were in no interruptions in the sequence of increasing atomic numbers. In addition, the relationship of the f-block to the other blocks of the periodic table also becomes easier to see.

For the previous reason, this research is motivated by mentioned gaps; it seems largely fit with an aspect standard form that fits on to the IUPAC's table of atomic number, groups, and periods. The paper tried to fill the current table's gaps focusing on the f-block 28 elements of Lanthanum to be inserted into the resulting space. In this paper, the table is the standard form of the IUPAC's table using the $3 \mathrm{~d}$ dimensional table projected by engineering projection drawing theory to draw the table. This feature presented in this research is rather important because it is based solely on atomic number, groups, and periods, the only criterion of the elements regarded as threeDimensional Method of element arrangement and representation in the periodic table rather than simple two dimensional recommended by IUPAC.

In this research, 3D-modified periodic table displays 7 Periods, and 12 Groups, in addition to 20 horizontal co- ordination's (named as Nada) involved in this research to determine and dispenses altogether the elements positions at the periodic system. The main motivation for this improvement layout is that it leads to the formation of a set of 7 projected views involving in the periodic table to solve the problem of spilt f-block of Lanthanum, (Lanthanides \& Actinides), unlike in the current table of the International Union of Pure and Applied Chemistry's (IUPAC). In addition, the study graphically predicted the positions of the 55 future elements starting from 119 till the element of 173 , developed in this research depending on the number of Periods (rows) and Groups (columns), which are depicted according to the IUPAC's table.

\section{Methods}

The research is design to deal with the current periodic table, without any change in the arrangement of elements that vertically presents the periods, and horizontally the groups systemized in the IUPAC's table. The research methodology is design to fill these mentioned gaps in the periodic table (elements of Lanthanide and Actinide), without any change in the elements arrangement that presents the periods vertically, and the groups horizontally systemized by atomic number as in the IUPAC's table. Horizontally, rows (Periods) were divided into 7 steps starting from element No.1 down to element number (87), whereas at the (Z-coordinator) the columns (Groups) starting form element No. 1 (Hydrogen) till element No. 2 (Hilum), as all were vertically listed within (12) steps. Building on the 3d-dimentional shape, a third coordinator was needed in order to distribution the element in the third dimension, which is related to my daughter's name, named as "Nada" and divided for geometrical aspects into 20 coordinators, $\left(\right.$ Nada $\left._{\mathrm{N} 1 \cdots \mathrm{N} 2 \cdots \cdots \mathrm{N} 20}\right)$, in which the table body is divided into 4 perpendicular Phases $(1,2,3 \& 4)$, consequently the table vertically linked within 3dimentions into (4) parts by (4) Lanes (A,B,C and D). Therefore, the group of elements of Lanthanide and Actinide is easily relinked with the end of phrase (1) to produce the phase (2), which meant that two phrases (1\&2) are vertically rejoined at elements of (57) and (89) respectively and the periodic table is built in one unit (Figure 1). 


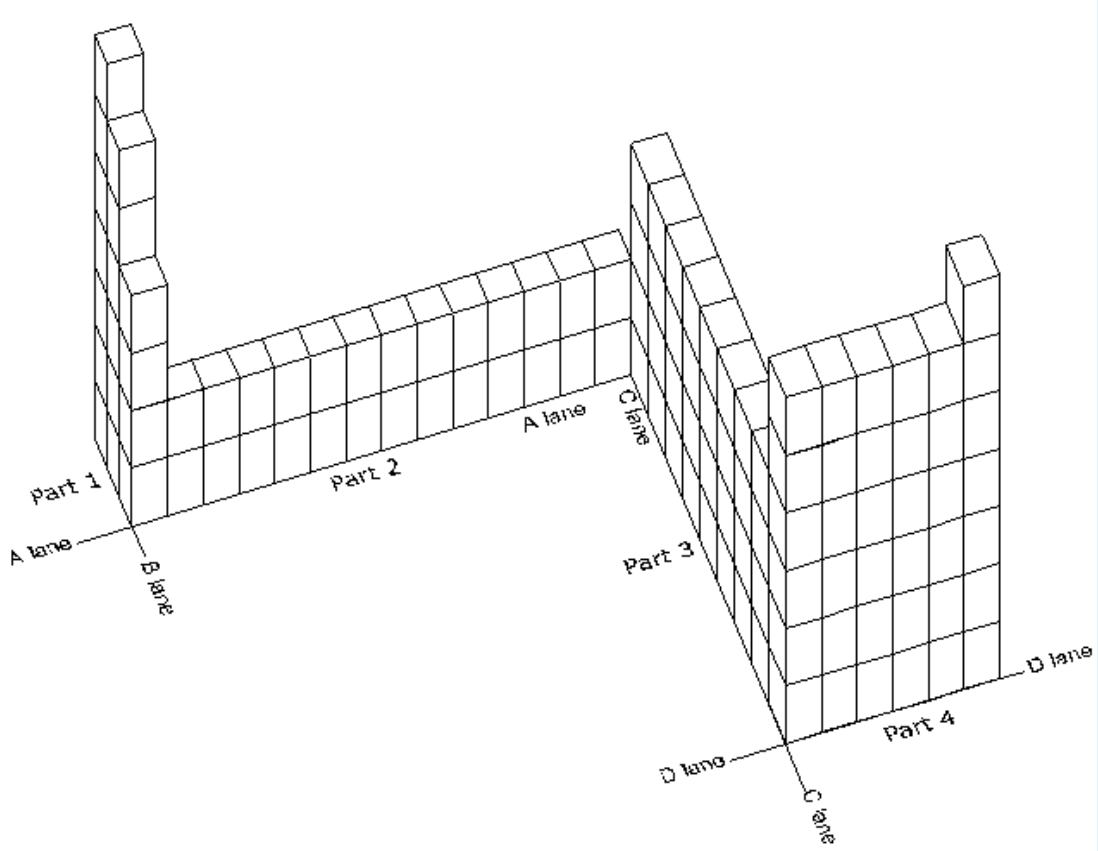

Figure 1: The main indications of the new 3-dimantional layout of the periodic table graphically shows the table's Phases (parts 1,2,3\&4), Lanes (A,B,C\&D), within 4 right-angled sides.

In general, these 4 parts that the new table is primarily can be detailed as follows:

- Phase 1: This part includes a set of (17) elements, which all are involved in Periods of $(1,2 \& 3)$, and in Groups of $(1,2,3,4,5,6 \& 7)$.

- Phase 2: This part includes set of (30) elements of Lanthanides \& Actinides, which are linked with the Phase (1) starting from elements: (57 \& 89). As a result of being this Phase in a different projection, (perpendicular with both Phases 1 and 3), thus all its elements are not listed within any Groups or Periods, therefore it is necessary to add a new direction, which is named as "Nada", and for geometrical aspects it is horizontally divided into 20 steps, $\left(N a d a_{N} 1 \ldots N 2 \ldots \ldots N 20\right)$, starting from phase (1) till (4).

- Phase 3: This part includes a set of (48) elements, which all are involved vertically in Periods of $(4,5,6 \& 7)$, and horizontally in Groups of $(3,4,5,6,7,8,9,10,11 \& 12)$. This phase is drawn to be paralleled to view of phase (1), (at the elements: 58 \& 90), whereas it is drawn to be projected with view of phase (2), (at the elements No. $71 \& 103)$.

- Phase 4: This part includes a set of (37) elements, which all are involved horizontally in Periods of $(1,2,3,4,5,6 \& 7)$, and vertically in one Group (number 12). Also, in this research Phase (4) is drawn perpendicularly with Phase (3), (elements from 30,48,80\&112).

Therefore, the new table was divided into (4) parts, which all were drawn for geometrical aspects within perpendicular projections, which needed to be determined by specific Lanes that have signs started by Lane (A) at the Phase (1), and Land (B) at the Phase (2), and the Lane (C) at Phase (3), and finally Lane (C) at Phase (4), (Figure 2). 


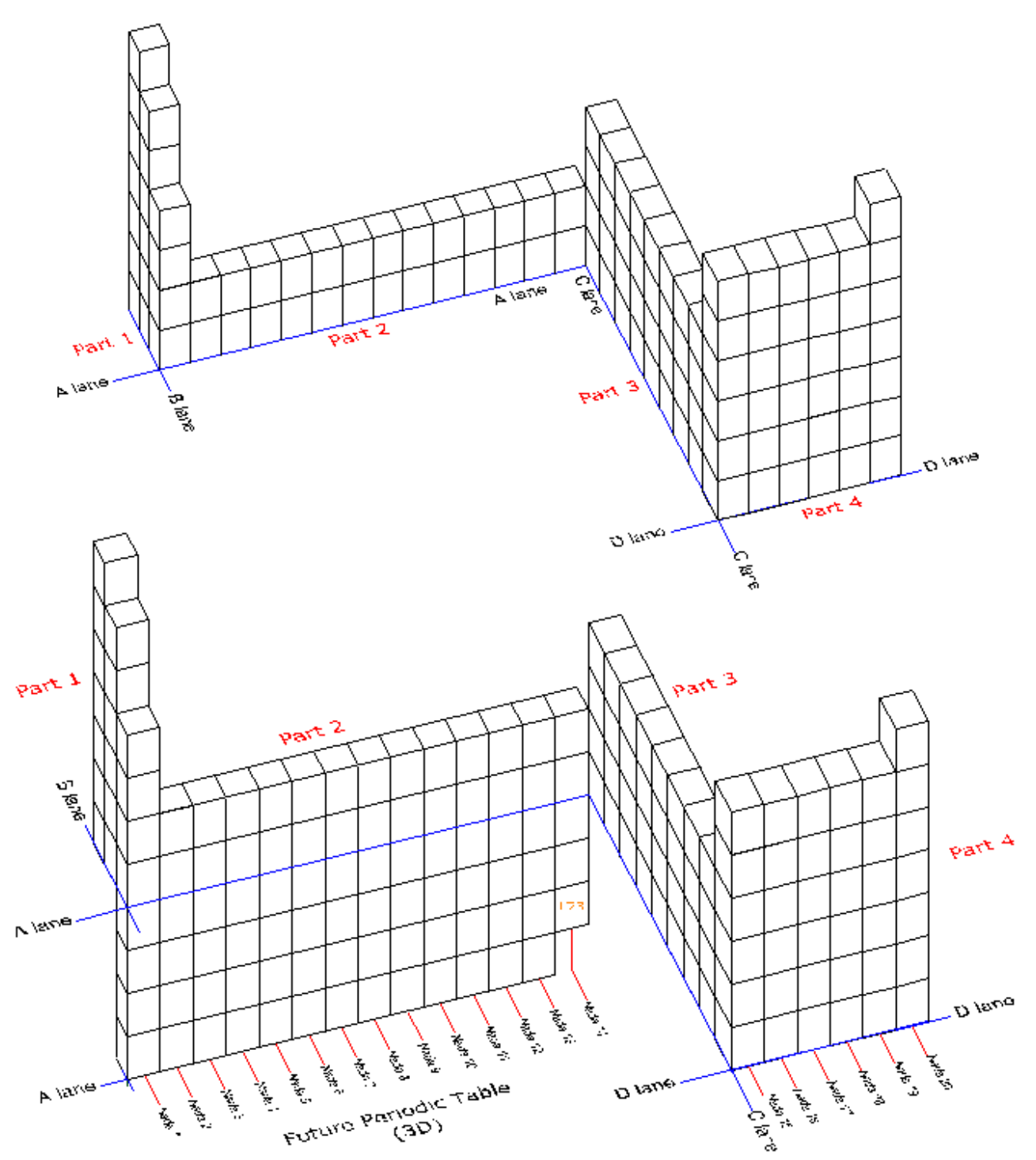

Figure 2: The new 3-dimantional layout of the periodic table graphically shows the predicted positions of these additional future elements from 119 (at Nada1) till 173.

As a result, the table is divided into 4 perpendicular Phases. Starting from Lane A and till Lanes (B,C and D), till Hilum element, there are (20) steps named "Nada $1 \ldots \mathrm{N} 2 \ldots . \mathrm{N} 20 "$, which are indicating the position of elements assemblies at each part of the 4 Phases of table. By using the projection drawing method, the Lanthanide \& Actinide, (30 elements), were reattached back to link at element number 56 and 88 respectively, and to be vertically linked to Groups (3) and the Periods (1 and 2). This perpendicular connection allowed both Phases (1\&2) to joined at Lanes (A and B), and also to Phases ( $2 \& 3$ ) to be joined at Lane (B and $C$ ), which is it the end of both the Lanthanide \& Actinide assemblies (Figure 3). 


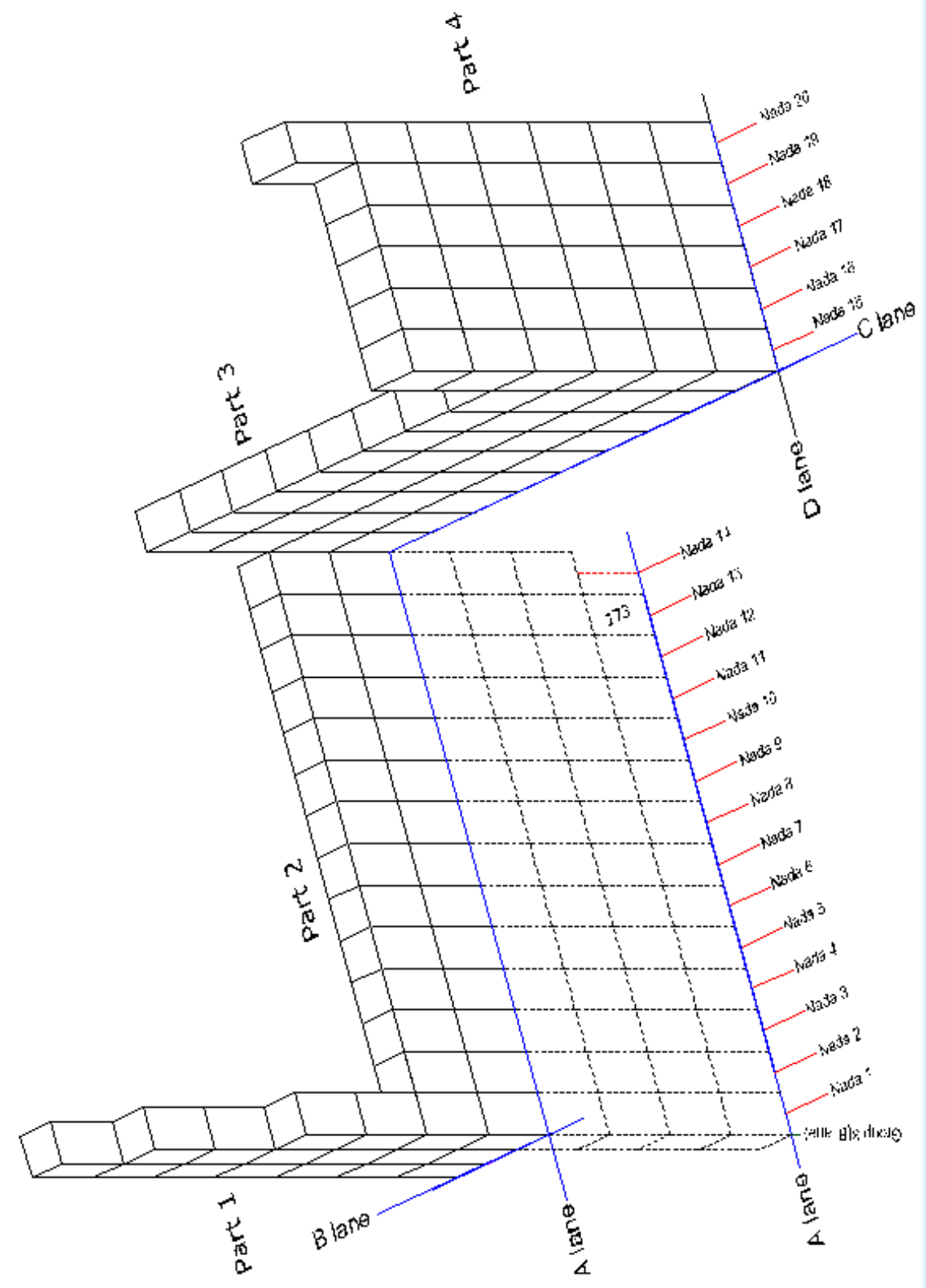

Figure 3: Future elements in (3D) Periodic Table.

\section{Results and Discussion}

\section{Building the Pattern}

As mentioned earlier, the new 3-dimentional table obtained in this study is consisted from 118 elements into (4) parts (Phases), which are drawn by using the projection drawing method to be right angular parts. In order to identify the patterns obtained from this table, all elements and their properties in each part will be separately detailed. Therefore, projected views (Top, Right, Left, Back, and Frontal views), with all properties \& details of their accumulated elements will be listed, and as following: 


\section{Medicinal \& Analytical Chemistry International Journal}

Frontal View of the New Table: If you have viewed the table from this angle, the view of (12) elements from Phase (1), and (36) elements from Phase (2) will be appeared in this projected view, whereas all elements at Phases (2) and (4) will be missed. The Figure and Table 1 graphically detailed view of this elements' arrangement.

\begin{tabular}{|c|c|c|c|c|c|}
\hline $\begin{array}{c}\text { Phase } \\
(1,2,3 \& 4)\end{array}$ & $\begin{array}{c}\text { Period } \\
(1,2,3,4,5,6 \& 7)\end{array}$ & $\begin{array}{c}\text { Group } \\
(1,2,3,4,5,6,7,8,9,10,11 \& 12)\end{array}$ & \begin{tabular}{c|}
$\mathbf{N a D a}_{(\mathbf{n})}$ \\
$(1,2,3,4,5,6,7,8,9,10,11,12$, \\
$13,14,15,16,17,18,19 \& 20)$ \\
\end{tabular} & Lane $(A, B, C \& D)$ & Elements \\
\hline \multirow{2}{*}{1} & $1,2,3,4,5,6,7$ & 1 & \multirow{4}{*}{1} & \multirow{2}{*}{ A } & $\mathrm{H}, \mathrm{Li}, \mathrm{Na}, \mathrm{K}, \mathrm{Rb}, \mathrm{Cs}, \mathrm{Fr}$ \\
\hline & $2,3,4,5,6,7$ & 2 & & & Be,Mg,Ca,Sr,Ba,Ra \\
\hline \multirow{2}{*}{$1+2$} & 4,5 & \multirow{2}{*}{3} & & $\mathrm{R}+\mathrm{A}$ & Sc,Y $Y$ \\
\hline & 6,7 & & & $\mathrm{~B}+\mathrm{A}$ & La,Ac \\
\hline 3 & 4 & $4,5,6,7,8,9,10,11,12$ & \multirow{8}{*}{15} & $\mathrm{C}$ & $\mathrm{Ti}, \mathrm{V}, \mathrm{Cr}, \mathrm{Mn}, \mathrm{Fe}, \mathrm{Co}, \mathrm{Ni}$ \\
\hline $3+4$ & 4 & 12 & & $\mathrm{D}+\mathrm{C}$ & $\mathrm{Zn}$ \\
\hline 3 & \multirow[t]{2}{*}{5} & $4,5,6,7,8,9,10,11,12$ & & $\mathrm{C}$ & $\begin{array}{c}\mathrm{Zr}, \mathrm{Nb}, \mathrm{Mo}, \mathrm{Tc}, \mathrm{Ru}, \mathrm{Rh}, \mathrm{PD} \\
\text {,Ag }\end{array}$ \\
\hline $3+4$ & & 12 & & $\mathrm{D}+\mathrm{C}$ & Cd \\
\hline 3 & \multirow[t]{2}{*}{6} & $4,5,6,7,8,9,10,11,12$ & & $\mathrm{C}$ & $\underset{u}{\text { Hf,Ta,W,Re,Os,Ir,Pt,A }}$ \\
\hline $3+4$ & & 12 & & $\mathrm{D}+\mathrm{C}$ & $\mathrm{Hg}$ \\
\hline 3 & \multirow[t]{2}{*}{7} & $4,5,6,7,8,9,10,11,12$ & & $\mathrm{C}$ & $\begin{array}{c}\text { Rf,Db,Sg,Bh,Hs,Mt,Ds, } \\
\text { Rg }\end{array}$ \\
\hline $3+4$ & & 12 & & $\mathrm{C}+\mathrm{D}$ & Cn \\
\hline
\end{tabular}

Table 1: Frontal view of the table and details of its accumulated elements.

Top View: If you have a look to the table from this angle, the view of (3) elements at Phase (1), (element of $S c$ is shared with Phase (2) at the Lane A\&B), and (15) elements at Phase (2), (element $L u$ is shared with Phase (3) at the Lane B\&C), and (10) elements at Phase (3), (element $B$ is shared with Phase (4) at the Lane C\&D), and 6 elements at Phase (4), (element $B$ is shared with Phase (3) at the Lane D\&C), will be appeared in this projected view. The figure and table 2 graphically detailed this view.

\begin{tabular}{|c|c|c|c|c|c|}
\hline $\begin{array}{c}\text { Phase } \\
(1,2,3 \& 4)\end{array}$ & $\begin{array}{c}\text { Period } \\
(1,2,3,4,5,6 \& 7)\end{array}$ & $\begin{array}{c}\text { Group } \\
(1,2,3,4,5,6,7,8,9,10,11 \& 12)\end{array}$ & \begin{tabular}{|c|}
$\mathbf{N a D a}$ \\
$1,2,3,4,5,6,7,8,9,10,11,12,13$ \\
$14,15,16,17,18,19 \& 20)$
\end{tabular} & $\begin{array}{c}\text { Lane } \\
(\mathrm{A}, \mathrm{B}, \mathrm{C} \& \mathrm{D})\end{array}$ & Elements \\
\hline 1 & \multirow{3}{*}{$1,2,3$} & \multirow{2}{*}{1,2} & \multirow{2}{*}{1} & A & H,Be \\
\hline $1+2$ & & & & $A+B$ & Sc \\
\hline 2 & & 3 & $\begin{array}{c}1,2,3,4,5,6,7,8,9,10,11,12,13 \\
14\end{array}$ & B & \begin{tabular}{|c|} 
Ce,Pr,Nd,Pm,Sm,Eu,Gd, \\
Tb,Dy,Ho,Er,Tm,Yb
\end{tabular} \\
\hline \multirow{2}{*}{$2+3$} & \multirow{2}{*}{4} & \multirow{2}{*}{$4,5,6,7,8,9,10,11$} & \multirow{3}{*}{15} & $\mathrm{~B}+\mathrm{C}$ & Lu \\
\hline & & & & $\mathrm{C}$ & Ti,V,Cr,Mn,Fe,Co,Ni,Cu \\
\hline \multirow{2}{*}{$3+4$} & 6 & \multirow{3}{*}{12} & & $\mathrm{C}+\mathrm{D}$ & B \\
\hline & 2 & & $15,16,17,18,19$ & \multirow{2}{*}{ D } & $\mathrm{C}, \mathrm{N}, \mathbf{O}, \mathrm{F}$ \\
\hline 4 & 1 & & 20 & & He \\
\hline
\end{tabular}

Table 2: Top view of the table and details of its accumulated elements.

Right-Side View: If you have a look to the table from this angle, the view of (3) Phases (1,2 and 4) will be viewed, whereas Phase 3 will be missed. In this view, (7) elements at Phase (1), (elements La\&Ac are shared with Phase 2 at the Land A\&B), and 15 elements at Phase 2, (elements
Nh\&Ti are shared with Phase 4 at the Land D\&C), and (37) elements at Phase (4), (at the Land D), will be appeared in this projected view. The Figure and Table 3 graphically detailed this view. 


\begin{tabular}{|c|c|c|c|c|c|}
\hline $\begin{array}{c}\text { Phase } \\
(1,2,3 \& 4)\end{array}$ & $\begin{array}{c}\text { Period } \\
(1,2,3,4,5,6 \& 7)\end{array}$ & $\begin{array}{c}\text { Group } \\
(1,2,3,4,5,6,7,8,9,10,11, \\
\& 12)\end{array}$ & \begin{tabular}{|c|}
$\mathbf{N a d a}_{\mathbf{n}} \mathbf{n}$ \\
$(1,2,3,4,5,6,7,8,9,10,11,12,13,14$, \\
$15,16,17,18,19, \& 20)$
\end{tabular} & $\begin{array}{c}\text { Lane } \\
(\mathrm{A}, \mathrm{B}, \mathrm{C} \& \mathrm{D})\end{array}$ & Elements \\
\hline 1 & $1,2,3$ & 1,2 & \multirow{3}{*}{1} & $\bar{A}$ & H,Be,Mg \\
\hline \multirow{2}{*}{$1+2$} & 4,5 & \multirow[b]{3}{*}{3} & & $\mathrm{~B}$ & Sc,Y $Y$ \\
\hline & 6,7 & & & $\mathrm{~A}+\mathrm{B}$ & La,C \\
\hline 2 & 6 & & $2,3,4,5,6,7,8,9,10,11,12,13,14$ & B & $\begin{array}{c}\text { Ce,Pr,Nd,Pm,Sm,Eu, } \\
\text { Gd,Tb,Dy,Ho,Er,Tm, } \\
\text { Yp }\end{array}$ \\
\hline 3 & 1 & \multirow{8}{*}{12} & 20 & \multirow{6}{*}{ D } & He \\
\hline \multirow{5}{*}{4} & 2 & & & & $\mathrm{~B}, \mathrm{C}, \mathrm{N}, \mathrm{O}, \mathrm{F}, \mathrm{Ne}$ \\
\hline & 3 & & & & $\mathrm{Al}, \mathrm{Si}, \mathbf{P}, \mathrm{S}, \mathrm{Ci}, \mathrm{Ar}$ \\
\hline & 4 & & $15,16,17,18,19,20$ & & $\mathrm{Ga}, \mathrm{Ge}, \mathrm{As}, \mathrm{Se}, \mathrm{Br}, \mathrm{Kr}$ \\
\hline & 5 & & & & In,Sn,Sb,Te,I,Xe \\
\hline & 6 & & & & Pb,Bi,Po,At,Rn \\
\hline $3+4$ & \multirow{2}{*}{7} & & 15 & $\mathrm{D}+\mathrm{C}$ & Ti, Nh \\
\hline 4 & & & $16,17,18,19,20$ & D & Fi,Mc,Lv,Ts, Og \\
\hline
\end{tabular}

Table 3: Right side view of the table and details of its accumulated elements.

Left-Side View: This is the opposite side to Right-side view, (see table 3), thus if you have a look to the table from this angle, the view of (7) elements at Phase (1), (elements Fr \& Cs are shared with Phase (2) at Lane A\&B), and (15) elements at Phase (2), (elements $L r \& L u$ are shared with Phase 3 at Lane B\&C), and (2) elements at
Phase (3), (both elements are inserted with Phase (4) at Lane D\&C), and (33) elements at Phase (4), (elements $N h$, $T i$, In \& Ga are not appeared as they are located behind Phase 3 at Lane D\&C). The Figure and Table 4 graphically detailed this view.

\begin{tabular}{|c|c|c|c|c|c|}
\hline $\begin{array}{c}\text { Phase } \\
(1,2,3 \& 4)\end{array}$ & $\begin{array}{c}\text { Period } \\
(1,2,3,4,5,6 \& 7)\end{array}$ & $\begin{array}{c}\text { Group } \\
(1,2,3,4,5,6,7,8,9,10,11 \\
\& 12)\end{array}$ & $\begin{array}{c}\mathbf{N a d a}_{(\mathbf{n})} \\
(1,2,3,4,5,6,7,8,9,10,11,12,13,14 \\
15,16,17,18,19, \& 20)\end{array}$ & $\begin{array}{c}\text { Lane } \\
(A, B, C \& D)\end{array}$ & Elements \\
\hline 1 & $1,2,3,4,5$ & \multirow{2}{*}{1} & \multirow{2}{*}{1} & A & H,Li,Na,K,Rb \\
\hline $1+2$ & 6,7 & & & $\mathrm{~A}+\mathrm{B}$ & Cs,Fr \\
\hline & \multirow{3}{*}{6} & \multirow{3}{*}{3} & \multirow[b]{2}{*}{$2,3,4,5,6,7,8,9,10,11,12,13,14$} & \multirow[b]{2}{*}{ B } & \begin{tabular}{|c|} 
La,C \\
\end{tabular} \\
\hline 2 & & & & & \begin{tabular}{|c|} 
Ce,Pr,Nd,Pm,Sm,Eu,Gd, \\
Tb,Dy,Ho,Er,Tm,Yp
\end{tabular} \\
\hline $2+3$ & & & \multirow{2}{*}{15} & $\mathrm{~B}+\mathrm{C}$ & Lu \\
\hline 3 & \multirow[b]{2}{*}{4,5} & \multirow[b]{2}{*}{4} & & $\mathrm{C}$ & Zr,Ti \\
\hline 2 & & & $2,3,4,5,6,7,8,9,10,11,12,13,14$ & B & $\begin{array}{c}\text { Th,Pa,U,Np,Pu,Am,Cm, } \\
\text { Bk,Cf,Es,Fm,Md,No }\end{array}$ \\
\hline 2 & 7 & 3 & \multirow{2}{*}{15} & $\mathrm{~B}+\mathrm{C}$ & Lr \\
\hline 3 & $4,5,6,7$ & $4,5,6,7,8,9,10,11$ & & $\mathrm{C}$ & Rf,Hf,Zr,Ti \\
\hline \multirow{7}{*}{4} & 1 & 1 & 20 & \multirow{7}{*}{$\mathrm{C}$} & $\mathrm{He}$ \\
\hline & 2 & \multirow{6}{*}{12} & \multirow{2}{*}{$15,16,17,18,19,20$} & & $\mathrm{~B}, \mathrm{C}, \mathrm{N}, \mathrm{O}, \mathrm{F}, \mathrm{Ne}$ \\
\hline & 3 & & & & $\mathbf{A l}, \mathbf{S i}, \mathbf{P}, \mathbf{S}, \mathbf{C i}, \mathbf{A r}$ \\
\hline & 4 & & \multirow{4}{*}{$16,17,18,19,20$} & & $\mathrm{Ge}, \mathrm{As}, \mathrm{Se}, \mathrm{Br}, \mathrm{Kr}$ \\
\hline & 5 & & & & $\mathrm{Xe}, \mathrm{I}, \mathrm{Te}, \mathrm{Sb}, \mathrm{Sn}$ \\
\hline & 6 & & & & Pb,Bi,Po,At, Rn \\
\hline & 7 & & & & Og,Ts,Lv,Mc,Fi \\
\hline
\end{tabular}

Table 4: Left-side view of the table and details of its accumulated elements. 
Back-Side View: This is the opposite side to Front-side view, (see table 1), thus if you have a look to the table from this angle, the view of (17) elements at Phase (1), (elements Lu\&Lr are shared with Phase 2 at Lane A\&B), and (2) elements, (Lu\&Lr are shared with Phase (1) at Lane A\&B), and (28) elements at Phase (3), ( $\mathrm{Zn}, \mathrm{Cd}, \mathrm{Hg}$ and $\mathrm{Cn}$ are disappeared behind Phase (4) at Lanes C \& D). The Figure 4 \& Table 5 graphically detailed this view.

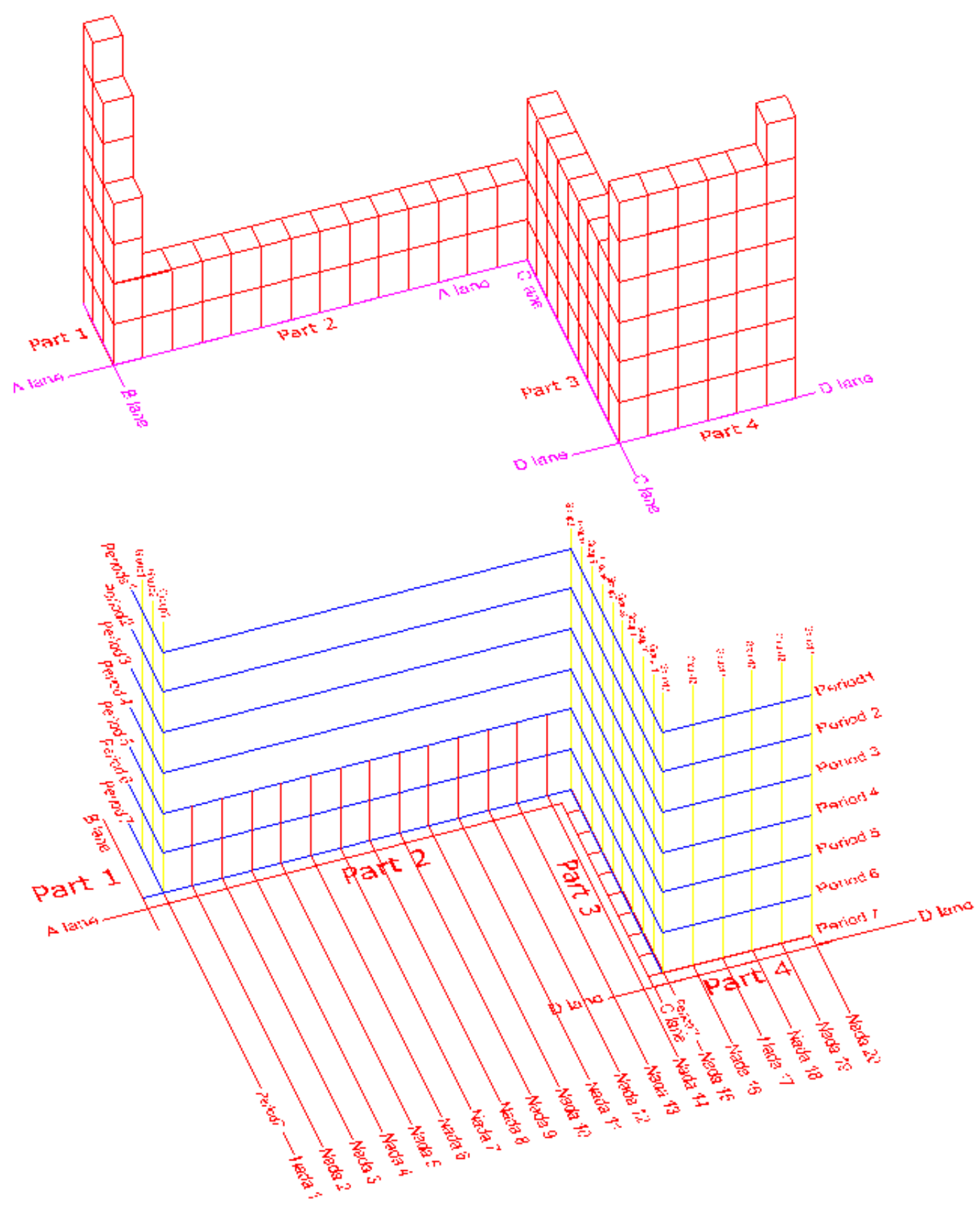

Figure 4: The new 3-dimantional layout of the periodic table graphically shows the main body parts of the table and also these vertical and horizontal coordinators of Periods, Groups, and Nadas. 


\begin{tabular}{|c|c|c|c|c|c|}
\hline $\begin{array}{c}\text { Phase } \\
(1,2,3 \& 4)\end{array}$ & $\begin{array}{c}\text { Period } \\
(1,2,3,4,5,6 \& 7)\end{array}$ & \begin{tabular}{|c|} 
Group \\
$(1,2,3,4,5,6,7,8,9,10,11$ \\
$\& 12)$
\end{tabular} & \begin{tabular}{|c|} 
Nada $_{(\mathbf{n})}$ \\
$(1,2,3,4,5,6,7,8,9,10,11,12,13$ \\
$14,15,16,17,18,19, \& 20)$ \\
\end{tabular} & $\begin{array}{c}\text { Lane } \\
(A, B, C \& D)\end{array}$ & Elements \\
\hline 4 & $1,2,3,4,5,6,7$ & 12 & 20 & $\mathrm{D}$ & $\mathrm{He}, \mathrm{Ne}, \mathrm{Ar}, \mathrm{Kr}, \mathrm{Xe}, \mathrm{Rn}, \mathrm{Og}$ \\
\hline \multirow{4}{*}{3} & 4 & \multirow{4}{*}{$4,5,6,7,8,9,10,11$} & \multirow{4}{*}{15} & \multirow{4}{*}{$\mathrm{C}$} & $\mathrm{Cu}, \mathrm{Ni}, \mathrm{Co}, \mathrm{Fe}, \mathrm{Mn}, \mathrm{Cr}, \mathrm{V}, \mathrm{Ti}$, \\
\hline & 5 & & & & Ag,Pd,Rh,Ru,Tc,Mo,Nb,Zr \\
\hline & 6 & & & & Au,Pt,Ir,Os,Re,W,Ta,Hf \\
\hline & 7 & & & & Rg,Ds,Mt,Hs,Bh,Sg,Db,Rf \\
\hline 2 & 6,7 & \multirow{2}{*}{3} & 14 & $\mathrm{~B}$ & Lu,Lr \\
\hline \multirow{3}{*}{1} & 4,5 & & \multirow{3}{*}{1} & \multirow{3}{*}{ A } & Sc,Y $Y$ \\
\hline & $2,3,4,5,6,7$ & 2 & & & Be,Mg,Ca,Sr,Ba,Ra \\
\hline & $1,2,3,4,5,6,7$ & 1 & & & $\mathrm{H}, \mathrm{Li}, \mathrm{Na}, \mathrm{K}, \mathrm{Rb}, \mathrm{Cs}, \mathrm{Fr}$ \\
\hline
\end{tabular}

Table 5: Back-side view of the table and details of its accumulated elements.

Bottom-Side View: This is the opposite side to Top-side view, (see table 2). However, if you have a look to the table from this angle you can draw two views (due to the intersection between Phases (1\&2) at Lanes A\&B, therefore these views are similar but the only difference is at the one position, in which the element $A c$ is placed in one view instead element $T h$ in the other. The figure 5 \& table 6 graphically detailed this view.

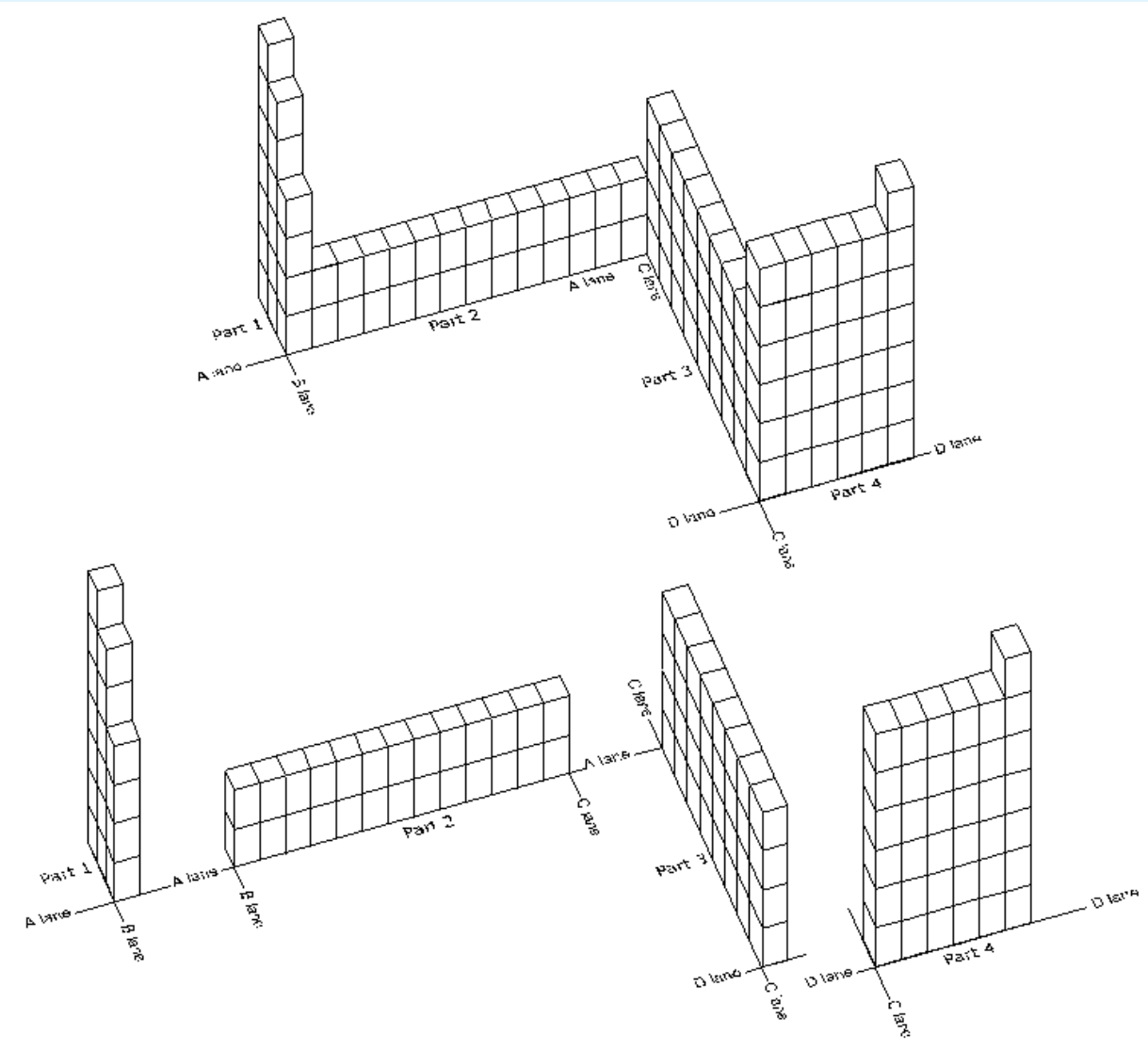

Figure 5: The new 3-dimantional layout of the periodic table graphically shows the main body parts of the tables 1-4 and their coordinators (Lanes A,B,C, \&D). 


\section{Medicinal \& Analytical Chemistry International Journal}

\begin{tabular}{|c|c|c|c|c|c|}
\hline $\begin{array}{c}\text { Phase } \\
(1,2,3 \& 4)\end{array}$ & $\begin{array}{c}\text { Period } \\
(1,2,3,4,5,6 \& 7)\end{array}$ & $\begin{array}{c}\text { Group } \\
(1,2,3,4,5,6,7,8,9 \\
10,11, \& 12)\end{array}$ & $\begin{array}{c}\mathbf{N a d a}_{(\mathbf{n})} \\
(1,2,3,4,5,6,7,8,9,10,11,12,13,14,15 \\
16,17,18,19, \& 20)\end{array}$ & $\begin{array}{c}\text { Lane } \\
(\mathrm{A}, \mathrm{B}, \mathrm{C} \& \mathrm{D})\end{array}$ & Elements \\
\hline 1 & \multirow{7}{*}{7} & 1,2 & \multirow{2}{*}{1} & $\mathrm{~A}$ & Fr,Ra \\
\hline $1+2$ & & 3 & & $\mathrm{~A}+\mathrm{B}$ & Ac/Th \\
\hline \multirow[t]{2}{*}{2} & & \multirow[t]{2}{*}{$4,5,6,7,8,9,10,11$} & \multirow[t]{2}{*}{$2,3,4,5,6,7,8,9,10,11,12,13,14$} & \multirow[t]{2}{*}{ B } & $\begin{array}{c}\mathrm{Pa}, \mathrm{U}, \mathrm{Np}, \mathrm{Pu}, \mathrm{Am}, \mathrm{Cm}, \mathrm{Bk}, \mathrm{Cf}, \mathrm{Es}, \\
\text { Fm }\end{array}$ \\
\hline & & & & & Md,No \\
\hline 3 & & \multirow{3}{*}{12} & \multirow{2}{*}{15} & $\mathrm{C}$ & Rf,Db,Sg,Bh,Hs,Mt,Ds,Rg \\
\hline $3+4$ & & & & $\mathrm{C}+\mathrm{D}$ & $\mathrm{Nh}$ \\
\hline 4 & & & $16,17,18,19,20$ & $\mathrm{D}$ & Fi,Mc,Lv,Ts,Og \\
\hline
\end{tabular}

Table 6: Bottom-side view of the table and details of its accumulated elements.

\section{Extensible to Expanding Future Elements}

According to scientific researches, it is expected that the end of the expanding future table of the elements would stop at the element of (173). Therefore, this research is designed within the 3dimentional layout to deal with such growth, and that needed only to extend the current Groups from (7) to peak at (11). The extensible to expanding future table is started at element (119), and ended at (173), all that are detailed in Table 7 \& Figures 6-11.

\begin{tabular}{|c|c|c|c|c|c|}
\hline $\begin{array}{c}\text { Phase } \\
(1,2,3 \& 4)\end{array}$ & $\begin{array}{c}\text { Period } \\
(1,2,3,4,5,6 \& 7)\end{array}$ & $\begin{array}{c}\text { Group } \\
(1,2,3,4,5,6,7,8,9 \\
10,11, \& 12)\end{array}$ & \begin{tabular}{|c|} 
Nada (n) \\
$(1,2,3,4,5,6,7,8,9,10,11,12,13$ \\
$14,15,16,17,18,19, \& 20)$
\end{tabular} & $\begin{array}{c}\text { Lane } \\
(\mathrm{A}, \mathrm{B}, \mathrm{C} \& \mathrm{D})\end{array}$ & Future Elements No. \\
\hline 1 & $8,9,10,11$ & \multirow{5}{*}{3} & 1 & $\mathbf{A}$ & $\mathbf{1 1 9}, 133,147,161$ \\
\hline \multirow{4}{*}{2} & 8 & & \multirow{3}{*}{$2,3,4,5,6,7,8,9,10,11,12,13,14$} & B & $\begin{array}{c}120,121,122,123,124,125,126, \\
127,128,129,130,131,132\end{array}$ \\
\hline & 9 & & & B & $\begin{array}{c}134,135,136,137,138,139,140, \\
141,142,145,146\end{array}$ \\
\hline & 10 & & & $\mathrm{C}$ & $\begin{array}{c}148,149,150,151,152,153,154 \\
155,156,157,158,159,160\end{array}$ \\
\hline & 11 & & $2,3,4,5,6,7,8,9,10,11,12,13$ & C+D & $\begin{array}{c}162,163,164,165,166,167,168 \\
169,170,171,172,173\end{array}$ \\
\hline
\end{tabular}

Table 7: Details of table with the future additional elements.

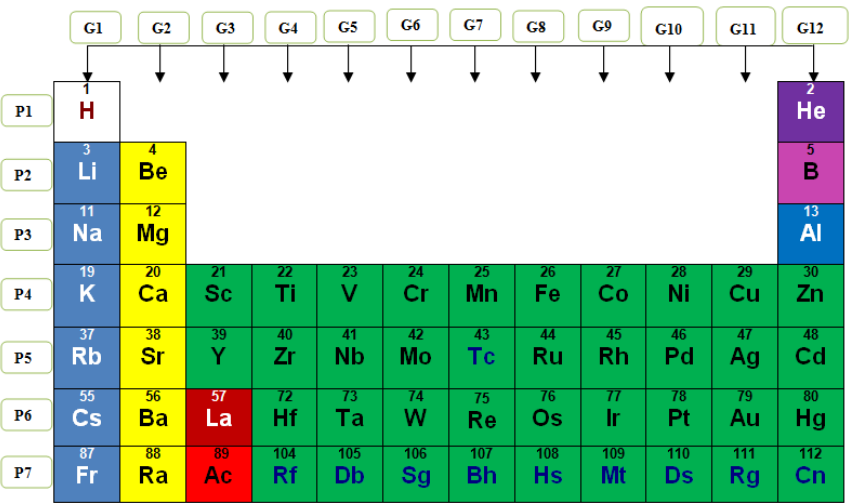

Figure 6: The new 3-dimantional layout of the periodic table graphically shows the main body of the table illustrated at the frontal view, where (G) is the Group's number, and (P) presents the Period's numbers. 


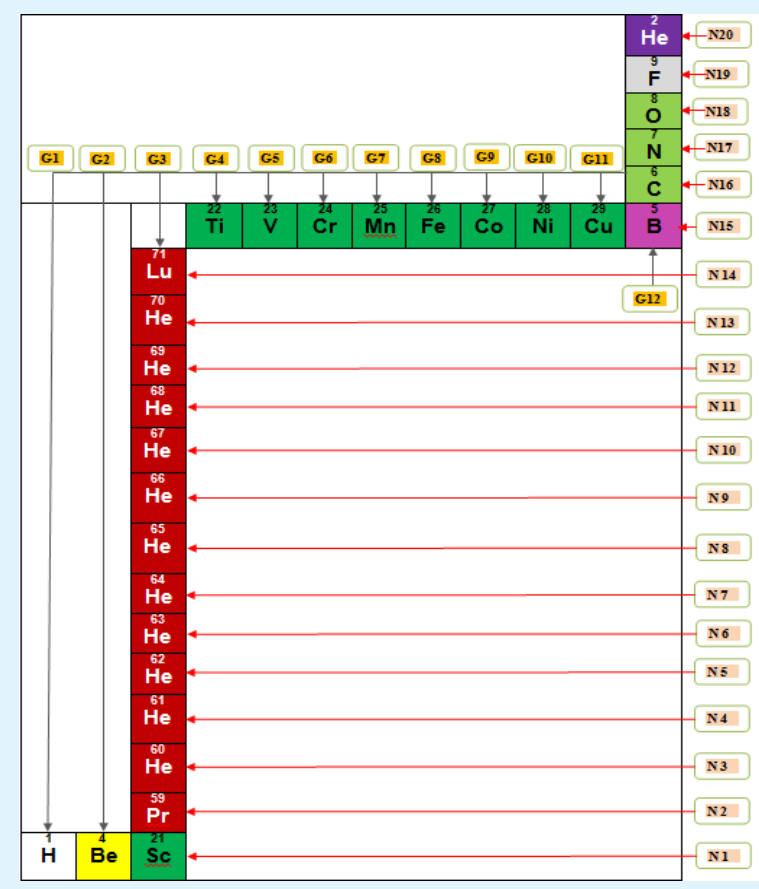

Figure 7: The new 3-dimantional layout of the periodic table graphically shows the main body of the table illustrated at the Top view, where (G) is the Group's number, and (N) presents the horizontal series numbers.

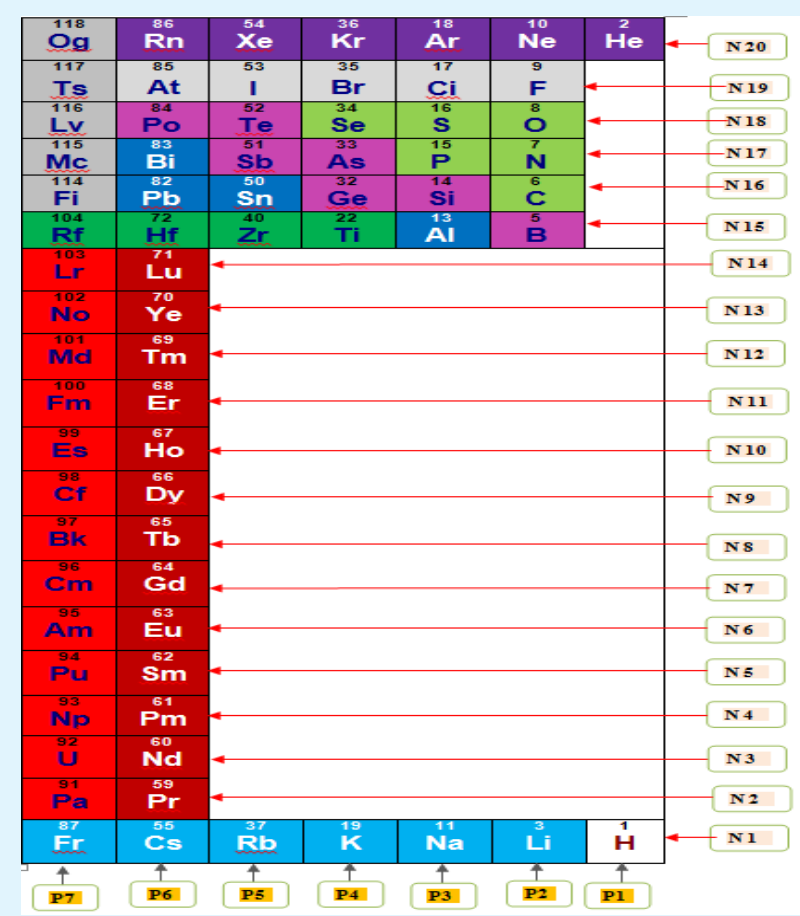

Figure 8: The new 3-dimantional layout of the periodic table graphically shows the main body of the table illustrated at the Left side view, where (G) is the Group's number, and $(\mathbf{N})$ presents the horizontal series numbers. 


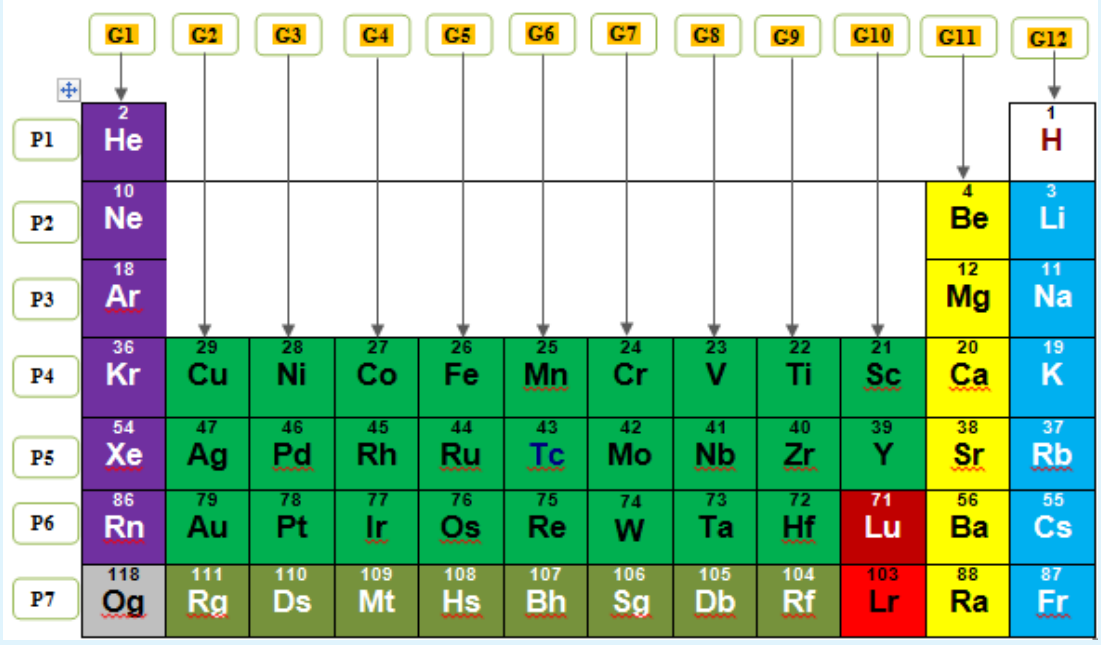

Figure 9: The new 3-dimantional layout of the periodic table graphically shows the main body of the table illustrated at the Back view, where (G) is the Group's number, and (P) presents the Period's numbers.

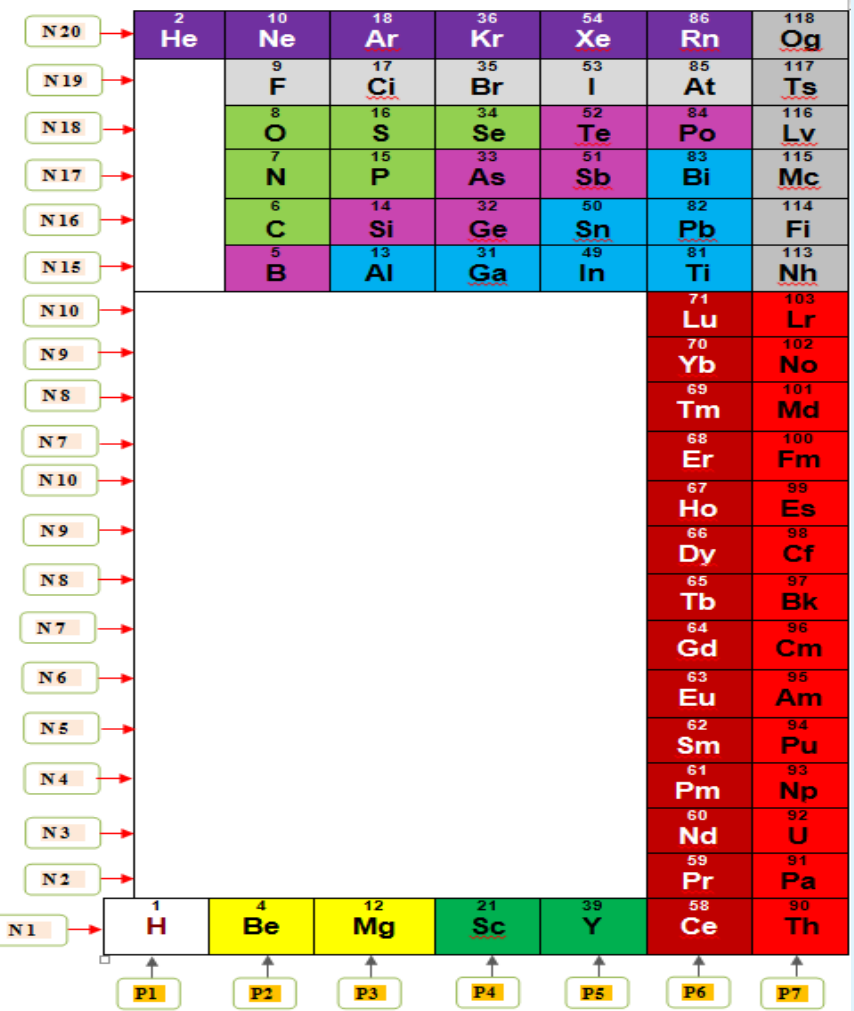

Figure 10: The new 3-dimantional layout of the periodic table graphically shows the main body of the table illustrated at the Right side view, where (P) is the Period's number, and (N) presents the horizontal series numbers. 


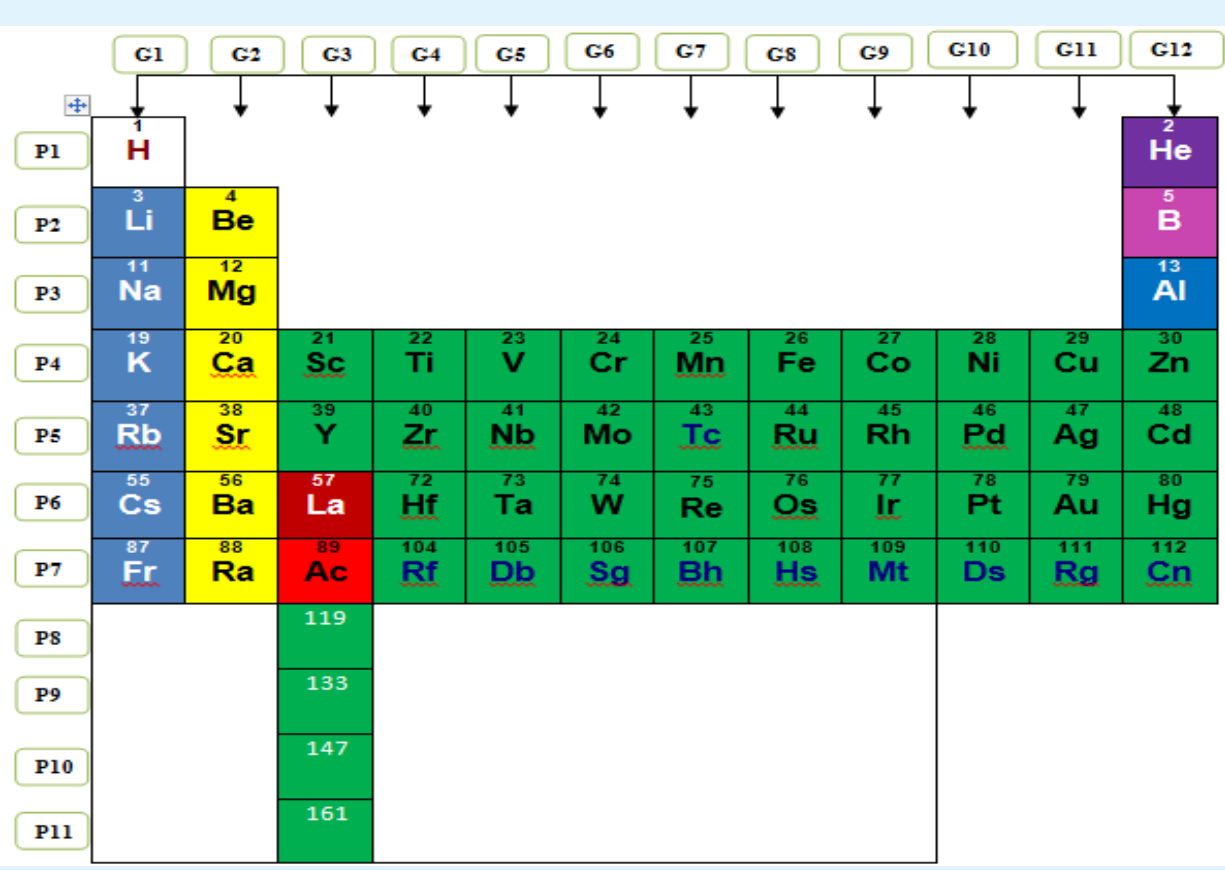

Figure 11: The new 3-dimantional layout of the periodic table graphically shows the main body of the table illustrated the prediction positions of future elements at the Frontal view, where (G) is the Group's number, and (P) presents the Period's numbers.

\section{Determining the Parts' Position at the Periodic Table}

In order to determine the precise position of each element at any part of the new table. Table 8 shows the view position and direction of each element according to its element number, Lane, Group, Period, Nada, and Phase at the periodic table. To build the model of this periodic table from cubic unites, views direction of each unit were identified by (5) directions code according to these views obtained from the three dimensional layout of the table phases, these views direction are; Front view, Left view, Right view, Back view, and Top view.

\begin{tabular}{|c|c|c|c|c|c|c|c|}
\hline No. & Elements & $\begin{array}{c}\text { Views } \\
\text { direction }\end{array}$ & Lane & Nada $(\mathbf{n})$ & Group & Period & Phase \\
\cline { 4 - 8 } & & A,B,C\&D) & $\begin{array}{c}(1,2,3,4,5,6,7,8,9,10, \\
11,13,14,15,16,17, \\
18,19, \& 20)\end{array}$ & $\begin{array}{c}(1,2,3,4,5,6,7,8,9,10, \\
11, \& 12)\end{array}$ & $(1,2,3,4,5,6 \& 7)$ & $(1,2,3 \& 4)$ \\
\hline $\mathbf{1}$ & $\mathbf{H}$ & R.F.Ba.L.T. & $\mathrm{A}$ & 1 & 1 & 1 & 1 \\
\hline $\mathbf{2}$ & $\mathbf{H e}$ & R.F.Ba.L.T. & $\mathrm{D}$ & 20 & 12 & 1 & 4 \\
\hline $\mathbf{3}$ & $\mathbf{L i}$ & F.Ba.L. & $\mathrm{A}$ & 1 & 1 & 2 & 1 \\
\hline $\mathbf{4}$ & $\mathbf{B e}$ & R.F.Ba.T. & $\mathrm{A}$ & 1 & 2 & 2 & 1 \\
\hline $\mathbf{5}$ & $\mathbf{B}$ & R.F.L.T. & $\mathrm{C}+\mathrm{D}$ & 15 & 12 & 2 & 4 \\
\hline $\mathbf{6}$ & $\mathbf{C}$ & R.L.T. & $\mathrm{D}$ & 16 & 12 & 2 & 4 \\
\hline $\mathbf{7}$ & $\mathbf{N}$ & R.L.T. & $\mathrm{D}$ & 17 & 12 & 2 & 4 \\
\hline $\mathbf{8}$ & $\mathbf{0}$ & R.L.T. & $\mathrm{D}$ & 18 & 12 & 2 & 4 \\
\hline $\mathbf{9}$ & $\mathbf{F}$ & R.L.T. & $\mathrm{D}$ & 19 & 12 & 2 & 4 \\
\hline $\mathbf{1 0}$ & $\mathbf{N e}$ & R.L.Ba. & $\mathrm{D}$ & 20 & 12 & 2 & 4 \\
\hline $\mathbf{1 1}$ & $\mathbf{N a}$ & F.Ba.L. & $\mathrm{A}$ & 1 & 1 & 3 & 1 \\
\hline
\end{tabular}




\begin{tabular}{|c|c|c|c|c|c|c|c|}
\hline 12 & Mg & R.F.Ba.T. & $\mathrm{A}$ & 1 & 2 & 3 & 2 \\
\hline 13 & Al & R.F.L.T. & $\mathrm{C}+\mathrm{D}$ & 15 & 12 & 3 & 4 \\
\hline 14 & $\mathbf{S i}$ & R.L. & $\mathrm{D}$ & 16 & 12 & 3 & 4 \\
\hline 15 & $\mathbf{P}$ & R.L. & D & 17 & 12 & 3 & 4 \\
\hline 16 & $S$ & R.L. & $\mathrm{D}$ & 18 & 12 & 3 & 4 \\
\hline 17 & $\mathbf{C i}$ & R.L. & D & 19 & 12 & 3 & 4 \\
\hline 18 & $\mathbf{A r}$ & R.L.Ba. & D & 20 & 12 & 3 & 4 \\
\hline 19 & $\mathbf{K}$ & F.Ba.L. & A & 1 & 1 & 4 & 1 \\
\hline 20 & $\mathrm{Ca}$ & R.F.Ba.T. & $\mathrm{A}$ & 1 & 2 & 4 & 1 \\
\hline 21 & Sc & R.F.Ba.T. & $A+B$ & 1 & 3 & 4 & 1 \\
\hline 22 & Ti & F.Ba.L.T & $\mathrm{C}$ & 15 & 4 & 4 & 3 \\
\hline 23 & $\mathbf{V}$ & F.Ba.T. & $\mathrm{C}$ & 15 & 5 & 4 & 3 \\
\hline 24 & $\mathrm{Cr}$ & F.Ba.T. & $\mathrm{C}$ & 15 & 6 & 4 & 3 \\
\hline 25 & Mn & F.Ba.T. & $\mathrm{C}$ & 15 & 7 & 4 & 3 \\
\hline 26 & $\mathbf{F e}$ & F.Ba.T. & $\mathrm{C}$ & 15 & 8 & 4 & 3 \\
\hline 27 & Co & F.Ba.T. & $\mathrm{C}$ & 15 & 9 & 4 & 3 \\
\hline 28 & $\mathbf{N i}$ & F.Ba.T. & $\mathrm{C}$ & 15 & 10 & 4 & 3 \\
\hline 29 & $\mathbf{C u}$ & F.Ba.T. & $\mathrm{C}$ & 15 & 11 & 4 & 3 \\
\hline 30 & Zn & F. & $\mathrm{C}+\mathrm{D}$ & 15 & 12 & 4 & $3+4$ \\
\hline 31 & $\mathbf{G a}$ & $\mathrm{R}$. & $\mathrm{C}+\mathrm{D}$ & 15 & 12 & 4 & $3+4$ \\
\hline 32 & Ge & R.L. & $\mathrm{D}$ & 16 & 12 & 4 & 4 \\
\hline 33 & As & R.L. & $\mathrm{D}$ & 17 & 12 & 4 & 4 \\
\hline 34 & Se & R.L. & D & 18 & 12 & 4 & 4 \\
\hline 35 & $\mathrm{Br}$ & R.L. & $\mathrm{D}$ & 19 & 12 & 4 & 4 \\
\hline 36 & $\mathbf{K r}$ & R.L.Ba. & D & 20 & 12 & 4 & 4 \\
\hline 37 & $\mathbf{R b}$ & F.L.F. & A & 1 & 1 & 5 & 1 \\
\hline 38 & $\mathbf{S r}$ & F.Ba. & A & 1 & 2 & 5 & 1 \\
\hline 39 & $\mathbf{Y}$ & F.Ba.R. & $A+B$ & 1 & 3 & 5 & $1+2$ \\
\hline 40 & $\mathbf{Z r}$ & F.Ba.L. & $\mathrm{C}$ & 15 & 4 & 5 & 3 \\
\hline 41 & $\mathrm{Nb}$ & F.Ba.L. & $\mathrm{C}$ & 15 & 5 & 5 & 3 \\
\hline 42 & Mo & F.Ba.L. & $\mathrm{C}$ & 15 & 6 & 5 & 3 \\
\hline 43 & Tc & F.Ba.L. & $\mathrm{C}$ & 15 & 7 & 5 & 3 \\
\hline 44 & $\mathbf{R u}$ & F.Ba.L. & $\mathrm{C}$ & 15 & 8 & 5 & 3 \\
\hline 45 & $\mathbf{R h}$ & F.Ba.L. & $\mathrm{C}$ & 15 & 9 & 5 & 3 \\
\hline 46 & Pd & F.Ba.L. & $\mathrm{C}$ & 15 & 10 & 5 & 3 \\
\hline 47 & $\mathbf{A g}$ & F.Ba.L. & $\mathrm{C}$ & 15 & 11 & 5 & 3 \\
\hline 48 & Cd & F. & $\mathrm{C}+\mathrm{D}$ & 15 & 12 & 5 & $3+4$ \\
\hline 49 & In & $\mathrm{R}$. & $\mathrm{C}+\mathrm{D}$ & 15 & 12 & 5 & $3+4$ \\
\hline 50 & Sn & R.L. & $\mathrm{D}$ & 16 & 12 & 5 & 4 \\
\hline 51 & $\mathbf{S b}$ & R.L. & $\mathrm{D}$ & 17 & 12 & 5 & 4 \\
\hline 52 & Te & R.L. & $\mathrm{D}$ & 18 & 12 & 5 & 4 \\
\hline 53 & I & R.L. & D & 19 & 12 & 5 & 4 \\
\hline 54 & $\mathbf{X e}$ & R.L.Ba. & $\mathrm{D}$ & 20 & 12 & 5 & 4 \\
\hline 55 & Cs & F.L. Ba. & A & 1 & 1 & 6 & 1 \\
\hline 56 & $\mathbf{B a}$ & F.Ba. & $\mathrm{A}$ & 1 & 2 & 6 & 1 \\
\hline 57 & La & F. & $A+B$ & 1 & 3 & 6 & 1 \\
\hline 58 & $\mathbf{C a}$ & L. & $A+B$ & 1 & 3 & 6 & 2 \\
\hline 59 & Pr & F.L. & B & 2 & 3 & 6 & 2 \\
\hline 60 & Nd & F.L. & B & 3 & 3 & 6 & 2 \\
\hline
\end{tabular}




\begin{tabular}{|c|c|c|c|c|c|c|c|}
\hline 61 & Pm & F.L. & $\mathrm{B}$ & 4 & 3 & 6 & 2 \\
\hline 62 & Sm & F.L. & B & 5 & 3 & 6 & 2 \\
\hline 63 & $\mathbf{E u}$ & F.L. & B & 6 & 3 & 6 & 2 \\
\hline 64 & Gd & F.L. & B & 7 & 3 & 6 & 2 \\
\hline 65 & Tb & F.L. & B & 8 & 3 & 6 & 2 \\
\hline 66 & Dy & F.L. & B & 9 & 3 & 6 & 2 \\
\hline 67 & Ho & F.L. & B & 10 & 3 & 6 & 2 \\
\hline 68 & Er & F.L. & B & 11 & 3 & 6 & 2 \\
\hline 69 & Tm & F.L. & $\mathrm{B}$ & 12 & 3 & 6 & 2 \\
\hline 70 & $\mathbf{Y b}$ & F.L. & $\mathrm{B}$ & 13 & 3 & 6 & 2 \\
\hline 71 & Lu & F.L. & $\mathrm{B}$ & 14 & 3 & 6 & 2 \\
\hline 72 & Hf & F.Ba.T. & $\mathrm{C}$ & 15 & 4 & 6 & 3 \\
\hline 73 & $\mathbf{T a}$ & F.Ba.T. & $\mathrm{C}$ & 15 & 5 & 6 & 3 \\
\hline 74 & W & F.Ba.T. & $\mathrm{C}$ & 15 & 6 & 6 & 3 \\
\hline 75 & Re & F.Ba.T. & $\mathrm{C}$ & 15 & 7 & 6 & 3 \\
\hline 76 & Os & F.Ba.T. & $\mathrm{C}$ & 15 & 8 & 6 & 3 \\
\hline 77 & Ir & F.Ba.T. & $\mathrm{C}$ & 15 & 9 & 6 & 3 \\
\hline 78 & $\mathbf{P t}$ & F.Ba.T. & $\mathrm{C}$ & 15 & 10 & 6 & 3 \\
\hline 79 & $\mathbf{A u}$ & F.Ba.T. & $\mathrm{C}$ & 15 & 11 & 6 & 3 \\
\hline 80 & $\mathrm{Hg}$ & F. & $\mathrm{C}+\mathrm{D}$ & 15 & 12 & 6 & $3+4$ \\
\hline 81 & $\mathrm{Ti}$ & R. & $\mathrm{C}+\mathrm{D}$ & 15 & 12 & 6 & $3+4$ \\
\hline 82 & $\mathbf{P b}$ & R.L. & $\mathrm{D}$ & 16 & 12 & 6 & 4 \\
\hline 83 & $\mathbf{B i}$ & R.L. & D & 17 & 12 & 6 & 4 \\
\hline 84 & Po & R.L. & $\mathrm{D}$ & 18 & 12 & 6 & 4 \\
\hline 85 & At & R.L. & D & 19 & 12 & 6 & 4 \\
\hline 86 & Rn & R.L.Ba. & $\mathrm{D}$ & 20 & 12 & 6 & 4 \\
\hline 87 & Fr & F.L.F. & A & 1 & 1 & 7 & 1 \\
\hline 88 & $\mathbf{R a}$ & F.Ba. & $\mathrm{A}$ & 1 & 2 & 7 & 1 \\
\hline 89 & Ac & F. & $A+B$ & 1 & 3 & 7 & 1 \\
\hline 90 & Th & $\mathrm{R}$. & $A+B$ & 1 & 3 & 7 & 2 \\
\hline 91 & $\mathbf{P a}$ & L.R. & B & 2 & 3 & 7 & 2 \\
\hline 92 & $\mathbf{U}$ & L.R. & B & 3 & 3 & 7 & 2 \\
\hline 93 & $\mathrm{~Np}$ & L.R. & $\mathrm{B}$ & 4 & 3 & 7 & 2 \\
\hline 94 & $\mathbf{P u}$ & L.R. & B & 5 & 3 & 7 & 2 \\
\hline 95 & Am & L.R. & B & 6 & 3 & 7 & 2 \\
\hline 96 & $\mathrm{Cm}$ & L.R. & B & 7 & 3 & 7 & 2 \\
\hline 97 & $\mathbf{B k}$ & L.R. & B & 8 & 3 & 7 & 2 \\
\hline 98 & Cf & L.R. & B & 9 & 3 & 7 & 2 \\
\hline 99 & Es & L.R. & B & 10 & 3 & 7 & 2 \\
\hline 100 & Fm & L.R. & B & 11 & 3 & 7 & 2 \\
\hline 101 & Md & L.R. & B & 12 & 3 & 7 & 2 \\
\hline 102 & No & L.R. & B & 13 & 3 & 7 & 2 \\
\hline 103 & $\mathbf{L r}$ & L.R. & B & 14 & 3 & 7 & 2 \\
\hline 104 & Rf & F.Ba.T. & $\mathrm{C}$ & 15 & 4 & 7 & 3 \\
\hline 105 & Db & F.Ba.T. & $\mathrm{C}$ & 15 & 5 & 7 & 3 \\
\hline 106 & Sg & F.Ba.T. & C & 15 & 6 & 7 & 3 \\
\hline 107 & Bh & F.Ba.T. & $\mathrm{C}$ & 15 & 7 & 7 & 3 \\
\hline 108 & Hs & F.Ba.T. & $\mathrm{C}$ & 15 & 8 & 7 & 3 \\
\hline 109 & Mt & F.Ba.T. & $\mathrm{C}$ & 15 & 9 & 7 & 3 \\
\hline
\end{tabular}




\section{Medicinal \& Analytical Chemistry International Journal}

\begin{tabular}{|l|c|c|c|c|c|c|c|}
\hline $\mathbf{1 1 0}$ & Ds & F.Ba.T. & C & 15 & 10 & 7 & 3 \\
\hline $\mathbf{1 1 1}$ & Rg & F.Ba.T. & C & 15 & 11 & 7 & 3 \\
\hline $\mathbf{1 1 2}$ & Cn & F. & C+D & 15 & 12 & 7 & $3+4$ \\
\hline $\mathbf{1 1 3}$ & Nh & R. & C+D & 15 & 12 & 7 & $3+4$ \\
\hline $\mathbf{1 1 4}$ & Fi & R.L. & D & 16 & 12 & 7 & 4 \\
\hline $\mathbf{1 1 5}$ & Mc & R.L. & D & 17 & 12 & 7 & 4 \\
\hline $\mathbf{1 1 6}$ & Lv & R.L. & D & 18 & 12 & 7 & 4 \\
\hline $\mathbf{1 1 7}$ & Ts & R.L. & D & 19 & 12 & 7 & 4 \\
\hline $\mathbf{1 1 8}$ & Og & R.L.Ba. & D & 20 & 12 & 7 & 4 \\
\hline \multicolumn{7}{|l|}{ Views direction: F= Front view, L=Left view, R= Right view, Ba=Back view, T=Top view } \\
\hline
\end{tabular}

Table 8: Determining each parts position at the periodic table.

\section{Key Findings}

Throughout this paper, a new method of element arrangement and representation in the periodic table is achieved and elements positions were described in a three-dimensional model according to period and groups numbers in the periodic table. Results showed that. The findings from this study suggest that 3-dimensional method stresses continuity rather than implying breaks between (30) elements in the Lanthanide and Actinide at the f-block edge and thus the main body of the table at the down edge, whereas, the conventional 2-dimensional table fails to emphasize the continuity in the sequence of these elements. Correspondingly, according to 3D-method requirements the new table in this research consisted of 4 right-angled parts (Phases 1,2,3 and 4), and third coordinator named Nada (from 1 till 20), and due to the 3d-layout of table and these 4 parts, all elements in Phase (1 and2) are located at Nada (1 and 14) respectively, whereas elements of Phase (2) are located within range of Nada's from (1 till 14). In practice, elements in the new table were Elements in the new table were vertically arranged to (12) Groups instead (18) in the IUPAC's twodimensional table, which would seem to suggest that it helps to allow reattaching these separated groups of $\mathrm{f}$ block, Lanthanide and Actinide, to be offset below the rest of the periodic table, thus these gaps in the IUPAC's twodimensional table at Period (3) \& Periods (6\&7) and at elements $\mathrm{Ba}$ and $\mathrm{Ra}$ were filled. Considerations of individual blocks made it valid to deduce the possible periodic positions of (55) future elements within each (7) sides of the table, which made it possible to deduce the periodic positions valid for all the elements within each block. The results show that it can be concluded that the new stage of the verification of the 3-dimensional method autonomy is the use of the real position of the elements (Periods, Groups, and Nada's in all Phase 1,2,3,\&4) as an independent variable in describing the atomic number as well as properties of the elements and their compounds in the IUPAC's table.

Previous model's problems with the f-block position attached after $L a \& A c$ can be altered in this new layout to put on Phase (2) in the main body of the table. Similarly, (7) modifications of right-angled views are ranged at 4 sides instead one in IUPAC's two- dimensional table. This new 3-dimentional layout is fitted with the future elements and arranged till element number 173. Also, (2) modifications of the conventional projected views are obtained by frontal and back views of Phases (1 and 4). The third and fourth showed the right and left side views at the (1,2 and 4) Phases. Fifth and sixth table views showed the bottom views with new arrangements. All these projected sides of the Periodic table can help to open a new horizon to the future researches.

\section{Conclusion}

The new method in which the proposed 3-d periodic table can play a critical role in the teaching and learning of chemistry, from its inception, the form of the periodic table is proposed as its fundamental graphic representation to reattaching these separated groups of $\mathrm{f}$ block, Lanthanide and Actinide. This idea is easily reproduced by the linear succession of the elements when they are ranged in groups and periods by growing atomic number in IUPAC's two- dimensional table. In this research, a three-dimensional model is built on keeping the previous arrangement of atomic number used in Moseley and Glenn Seaborg's table (in IUPAC's table). Likewise, each one of these (7) new sides produced in this new model can be studied as a new case study. By adding an increasing on Groups number to be continued from (7) till (11), this new model can be suitable to absorb the future elements to deal with a future growth of elements starting from (No.119) till element number (173). 
Correspondingly, two other views were produced, in which the future elements were tabulated at Phase (2). In shortage of similar implications, such simple model may play a critical role in the teaching and learning of chemistry. Therefore, it can be concluded that despite common methods for calculation and determination, here are some simples and regulatory methods which control levels of active calculation ways among the Atomic Number.

\section{References}

1. Hinrichs GD (1869) On the classification and the atomic weights of the so-called chemical elements, with particular reference to Stas's determinations, Essex institute press, Vol 13.

2. Kaji M (2004) Discovery of the periodic law: Mendeleev and other researchers on element classification in the 1860s, in The periodic table: Into the 21st Century, In: Rouvray, D. H., King, R. Bruce; Research Studies Press, pp: 91.

3. Siegfried R (2008) From Elements to Atoms: A History of Chemical Composition, American Philosophical Society, pp: 4-6.

4. Jena P (2013) Beyond the Periodic Table of Elements: The Role of Superatoms. J Phys Chem Lett 4(9): 14321442.

5. Leigh G J (2019) IUPAC and the Periodic Table. Chemistry International 41(1): 6-9.

6. Deveson A C (2019) From the Periodic Table to Open Science. Chemistry Select 4(1): 2-4.

7. Karol P J (2009) The Mendeleev-Seaborg Periodic Table: Through Z=1138 and Beyond. J Chem Educ 79(1): 60.
8. Rampling J (2019) More than 2,000 years of elements: a prehistory of the periodic table. Nature 565 (7741): 563-564.

9. Koppenol W H (2002) Naming of new elements (IUPAC Recommendations 2002) Pure Appl Chem 74(5): 787-791.

10. Silberberg M S, Amateis P (2018) Chemistry: The Molecular Nature of Matter and Change. $8^{\text {th }}$ (Edn.), McGraw-Hill, New York.

11. Weinhold F, Bent H A (2007) News from the Periodic Table: An Introduction to Periodicity Symbols, Tables, and Models for Higher-Order Valency and DonorAcceptor Kinships. J Chem Educ 84(7): 1145.

12. Lopper M E (2019) A Digital Periodic Table That Instructors Can Use in the Classroom to Highlight Elements and Illustrate Periodic Trends. J Chem Educ 96(2): 387-389.

13. Reedijk J, Tarasova N (2019) The International Year of the Periodic Table 2019. Chem Int 41(1): 2-5.

14. Matlin S A, Mehta G, Hopf H, Krief A (2019) The Periodic Table of the Chemical Elements and Sustainable Development. Eur J Inorg Chem 2019(3940): 4170-4173.

15. Rogers R D (2019) 2019 Year of the Periodic Table. Cryst Growth Des 19(1): 1-2.

16. Guillaumont R (2019) Completion and Extension of the Periodic Table of Elements beyond Uranium. Comptes Rendus Physique. 